\title{
Correction to: Treatment of tannery wastewater in a pilot scale hybrid constructed wetland system in Arequipa, Peru
}

\author{
J. S. Pineda Zapana ${ }^{1}$ - D. S. Arán ${ }^{2}$ - E. F. Bocardo ${ }^{1}$ - C. A. Harguinteguy ${ }^{2}$ (i)
}

Published online: 21 December 2020

(c) Islamic Azad University (IAU) 2020

\section{Correction to: \\ International Journal of Environmental Science and \\ Technology (2020) 17:4419-4430 \\ https://doi.org/10.1007/s13762-020-02797-8}

In the list of author surnames, an author name was incorrectly stated in the original print and online files. The correct list of author names for this article should appear as:

Pineda Zapana, J.S., Arán, D.S., Bocardo, E.F. and Harguinteguy, C.A.
In the affiliation (1) was incorrectly stated in the original print and online files. The correct affiliation (1) for this article should appear as:

1 Environmental Engineering School, Faculty of Process Engineering, Universidad Nacional de San Agustín de Arequipa (UNSA), Arequipa, Perú

Publisher's Note Springer Nature remains neutral with regard to jurisdictional claims in published maps and institutional affiliations.
The original article can be found online at https://doi.org/10.1007/ s13762-020-02797-8.

\section{A. Harguinteguy}

c_harguinteguy@unc.edu.ar

1 Universidad Nacional de San Agustín de Arequipa, Arequipa, Perú

2 CONICET and Faculty of Exact, Physical and Natural Sciences, Multidisciplinary Institute of Plant Biology (IMBIV), National University of Córdoba, Córdoba, Argentina 